\title{
Do Tangible User Interfaces promote social behaviour during free play? A comparison of autistic and typically-developing children playing with passive and digital construction toys.
}

\author{
Gill A. Francis ${ }^{1}$ Will Farr ${ }^{2}$ Silvana Mareva ${ }^{3}$ Jenny L. Gibson ${ }^{1}$
}

\begin{abstract}
${ }^{1}$ Centre for Research on Play in Education, Development and Learning (PEDAL), University of Cambridge; ${ }^{2}$ Sussex Community NHS Trust; ${ }^{3}$ Cognition \& Brain Sciences Unit, University of Cambridge;
\end{abstract}

NB This is the post-peer-review version of a paper accepted in Research in Autism Spectrum Disorders. Correspondence to $\mathcal{F}$. Gibson:jlg53@cam.ac.uk

\begin{abstract}
Background. Little is known about the extent to which embodied digital mediation may support social engagement between children with or without autism (ASD) in free play settings. This study draws on Affordance theory and Sociocultural theory to investigate social play behaviours associated with use of a Tangible User Interface (TUI) during free play.

Method. The study used a detailed observational and descriptive design. Two groups of children with ASD and two groups of typically developing (TD) children were filmed during a 20-minute play session with either a passive toy, or a digital toy with a TUI. Behaviours were coded according to a scheme based on Parten's Play States. Data were described in terms of duration, frequency and the likelihood of transition to another state, given the current state.
\end{abstract}

Results. For TD children, Parallel and Associative were the most frequently observed Play States across both conditions. For those with ASD, Parallel Play and NonPlay-Related Conversation were the most frequent states in the passive condition, while Parallel and Associative Play were the most common in the TUI condition. This group demonstrated a longer duration of co-operative play with the TUI toy compared to TD children. Both groups showed higher frequencies of social play in the TUI condition.

Conclusions. Social play states can be effectively mediated by TUIs for both TD and ASD groups. For the ASD group, repetitive behaviour with a TUI may not be inhibitory to social engagement. Practitioners may consider making TUI enabled toys available during free play opportunities.

Index Terms-autism; tangible user interface; free play; social interaction

\section{INTRODUCTION}

Digital technology is increasingly recognised as having great potential as a supportive tool for addressing some of the daily-life challenges associated with autism (Fletcher-Watson \& Durkin, 2015; Goodwin, 2008). Nevertheless, concerns persist that digital technology may increase social isolation by exacerbating inherent social impairments experienced by some children with autism, through promoting more individualistic than social opportunities for interaction (Durkin \& Blades, 2009; Orsmond \& Kuo, 2011). In this paper, we argue that social isolation is not an inevitable consequence of digital technology. Rather, attention should be paid to the different types of digital technology available and the different affordances they offer.

The theory of affordance has its roots in Gibson's seminal text Ecological Approach to Visual Perception (Gibson, 1979). Gibson emphasised the role of the environment, including objects therein, in influencing the possibilities for action by a person/animal in that environment. The term Affordances is often used to refer to those characteristics of environments/objects that exert such influences. In addition, Pozzi and colleagues (Pozzi, Pigni, Vitari, Buonanno, \& Raguseo, 2016) have noted that modern interpretations of affordance emphasise the interaction between an actor and the environment. Thus the environment may set up necessary preconditions for a particular activity, but affordances will also depend on the actor's ability to perceive the potential for action.

This is a significant consideration when considering technologies that could support children to engage in social interaction and play. The 'preconditions' of the environmental and object properties should be considered alongside individual proclivities or abilities to engage in social interaction. In the current study, we focus on the analysis of interactions with one particular type of technology; Tangible User Interfaces (TUIs). TUIs are physical interfaces that allow users to interact with digital information. When created as toys, TUIs embed technology into graspable forms (see figure 2 below) and seek to engage users in physically and digitally mediated interaction (Ishii \& Ullmer, 1997). This allows children the freedom and opportunity to access play through subjective interpretation or via 'multiple points of entry' (Fernaeus, Tholander, \& Jonsson, 2008). Children choose how to play with the objects, and digital mediation crosses and transforms the physical/digital divide (Rogers, Scaife, Gabrielli, Smith, \& Harris, 2002). 
This interaction across the physical/digital divide not only provides new opportunities for interaction but can also potentially mediate for individuals who may have a neurodevelopmental disorder (Pares et al., 2004; Robins \& Dautenhahn, 2007; Tartaro \& Cassell, 2008). How exactly digital mediation works, however, or what 'active ingredients' cause change is still somewhat unclear (Levac, Rivard, \& Missiuna, 2012). One hypothesis is that introducing a TUI could mediate social behaviour both through the affordances of the object itself and through the enabling of contingent interaction.

Difficulties with contingent interaction can arise from disruption to developmental processes. For example, in the case of autism, difficulties are frequently observed in conversational contexts, where the process of building appropriately on the interlocutor's contribution can be a challenge (TagerFlusberg \& Anderson, 1991). Difficulties with contingency can also apply to object interaction, for example, if the timing of a response to an object's affordance from a child with autism is slower and less organised in comparison to the typical child (Torres et al., 2013). Smart implementation of digital technology could therefore be harnessed to provide more flexible, or more salient, opportunities for contingency. Previous studies with children with autism show that this could take many forms; interaction with a humanoid robot (Robins \& Dautenhahn, 2007), interactive environment (Maskey, Lowry, Rodgers, McConachie, \& Parr, 2014), touchscreen (Piper, O’Brien, Morris, \& Winograd, 2006) or digitally enhanced object (Hinske, Langheinrich, \& Lampe, 2008).

Returning to affordance theory, it is not only objects that influence behaviour but also environments (Pozzi et al., 2016). Given our interest in exploring the social aspects of TUIs, we first focus on social context as an environmental consideration. In social play, children navigate the complexities of the self and others in the choice of activity, tool use and rules of play. Such interactions have been theorised to be a key mechanism for childhood social development (Vygotsky, 1978), for example in learning to self-regulate, negotiate and compromise.

Research investigating the reciprocal relationship between social engagement and play reveals that the inclination to play is present in both children with ASD and TD children, but the impulse to play socially is more subdued in children with ASD than their TD peers (Williams et al., 1999; Wolfberg, 2009; Yuill, Strieth, Roake, Aspden, \& Todd, 2007). Group play and social initiation is within reach of many children with ASD, their challenge rests in sustaining joint attention over time (Holt \& Yuill, 2014; Wolfberg, BottemaBeutel, \& DeWitt, 2012). Thus, objects that can mediate the social aspects of play could potentially be beneficial.

\section{A. The present study}

This current study builds upon the Vygotskian idea of socially constructed learning and explores the affordances of TUIs and peer play environments through the lens of Constructionism (Papert \& Harel, 1991). According to Papert, learning is a highly situated process, embedded in context and constructed by the learner. Often this construction takes place around the shared creation of 'objects-to-think-with' (e.g. tools, toys or computer-programmes). Working within this framework, Ackermann (1996) describes learning as a dynamic dance between diving in and stepping out. 'Diving in' occurs as one is immersed in a situation, whereas 'stepping out' allows the actor to detach from the situation in order to reflect on it and learn. Thus, learning and play become inseparable, and disengagement does not necessarily signify an undesirable state. Indeed, alternation between solitary and social activity has been consistently observed during various types of peer play interactions (Guralnick \& Hammond, 1999; Robinson, Anderson, Porter, Hart, \& Wouden-Miller, 2003).

We therefore wished to examine how social aspects of the 'diving-in' and 'stepping-out' process play out using TUI vs Passive toys. In a previous study using fantasy playsets that afford pretence play, autistic children engaged in more socially oriented play when a toy was digitally configurable than when it was not (Farr, Yuill, \& Hinske, 2012). Similarly, directing children to build an object as pictured on a demonstration card has been associated with an increase in cooperative play and onlooking behaviours, when using a TUI toy compared to a passive toy (Farr, Yuill, \& Raffle, 2010).

The present study investigates a play scenario that combines both free play and construction toys. Free play with peers is thought to be a particularly stimulating context for children's social development of skills for collaboration, co-operation and negotiation (Gibson, Hussain, Holsgrove, Adams, \& Green, 2011; Gibson, Cornell, \& Gill, 2017). We use the term 'free play' here to denote play that has not been directed by adults, for example the scenario mentioned above where children built models from a template card (Farr, Yuill, \& Raffle, 2010). From a positive psychology perspective, free play is characterised as freely chosen, selfdirected, intrinsically motivated, rule-guided activity that is engaged in in non-stressful situations and states of being (Gray, 2013). Social free play may be particularly challenging for individuals with autism due to it requiring a high degree of behavioural flexibility and social awareness (Gibson et al., 2011).

Studying free play with a construction toy is warranted because previous research has demonstrated that autistic children are more likely to engage in this construction play, given a free choice (Holmes \& Willoughby, 2005). Holmes and Willoughby's study also shows that children engaged in construction play often do this in parallel to other children, rather than in collaboration. Therefore, we were particularly interested in whether a TUI construction toy would be associated with an increase in socially oriented play for both autistic and TD children.

In accordance with our earlier discussion of affordance, we were interested in the possibilities for action between autistic/non-autistic children and TUI/passive objects. Our ultimate goal was to understand more about the affordances of different play opportunities that could help inform educator decisions about the provision of play opportunities and objects. 


\section{Methods}

\section{A. Ethics}

Ethical review and permissions were granted from University of Sussex Psychology department ethical review board in June 2008.

Parents gave informed consent on behalf of their children. Children took part in the study by assent to join in the play activities. One autistic child declined to participate on this basis.

\section{B. Participants}

Six participants with a diagnosis of autism (age 8-11 years, $\mathrm{M}=10.6, \mathrm{SD}=1.51$ ) and six typically developing children took part in the study (age 7-9 years, $\mathrm{M}=8.16$, $\mathrm{SD}=0.752$ ). Autistic participants were all male and attended a special education provision for those with autism. Typically developing participants ( 1 female) were drawn from a mainstream school. Groups did not mix autistic and non-autistic children because the focus of research was to investigate the affordances of the technology within distinct groups.

All autistic children had diagnoses of autism spectrum disorder (ASD) and had no co-occurring conditions according to parent and teacher report. Children were assessed according to UK National Curriculum Speaking and Listening (S\&L) assessment guidelines to indicate baseline ability at the time of the study in 2010 (Qualifications, Curriculum, \& Authority, 1999). Levels ranged from 1a to 4c (ASD) and from $3 \mathrm{c}$ to $3 \mathrm{~b}$ (TD children). The most frequent S\&L level was $3 \mathrm{c}$, appropriate to the Year 3-4 age group (age 7 and 8). The most frequent S\&L level of the ASD group was lower than the TD group (2b) equivalent to the expected functioning language skills of a 5/6 year-old child. The TD group mode (3b) is equivalent to age 8 years.

\section{Procedures}

Children were put into small groups at tables in a quiet space and were provided with either a passive (LEGO) or TUI (Topobo) set of construction toys to play with for 20 minutes. On a separate occasion the same group of children was given the set of toys not previously received and left to play for 20 minutes. The order of presentation of the toys was randomised across the groups. In each play episode children were told, "you can make anything you want with this toy, you have 20 minutes to play with it." In order to offset the familiarity children may have with LEGO, both groups were exposed to Topobo for approximately two hours over a period of two weeks before the experiment.

There were three children per group, although one group was reduced to a pair when one child declined to participate - data from this child were not coded or analysed. There were four groups in total and groups did not mix autistic and non-autistic participants.

All groups were filmed for each of the 20-minute play sessions. This set of videos was originally collected, but not analysed, as part of a $\mathrm{PhD}$ investigating the use of TUIs for children with autism.

\section{Materials}

Topobo (see Fig. 1.) Topobo is a tangible user interface, a 3 -D toy requiring assembly and is programmable with kinetic memory (Raffle, Parkes, \& Ishii, 2004). Topobo allows objects to be created through interconnected plastic blocks, similar to $\mathrm{LEGO}^{\mathrm{TM}}$. Topobo was based on the naturally occurring fibbonacci number series (Raffle et al., 2004) resulting in more 'organic' creations that can walk and move and have comparative ratios similar to living creatures. Topobo blocks themselves are passive pieces, but when interconnected with a main body, known as an 'active', (see Fig. 2.) they can be programmed to move.

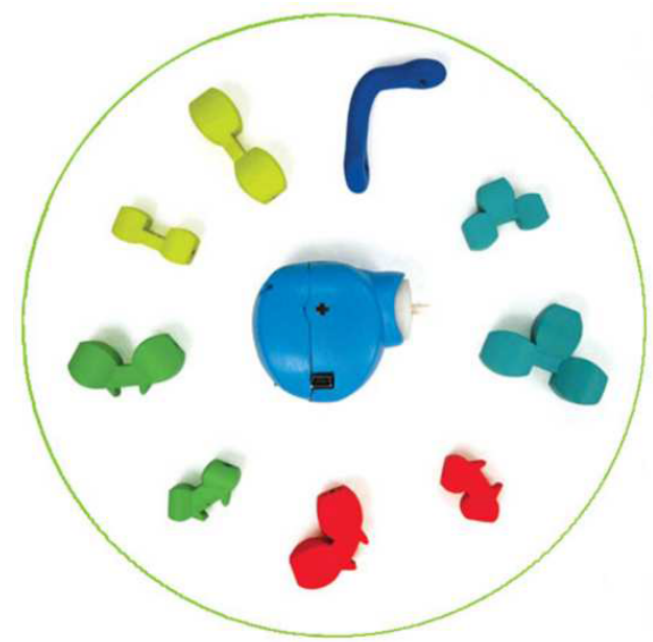

Figure 1: An example of an assembled and unassembled Topobo creature

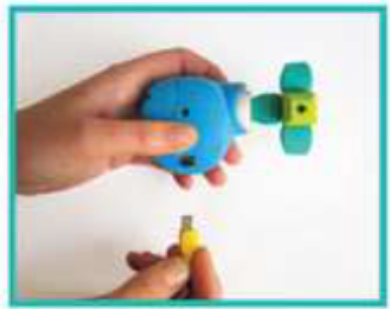

plug in the active

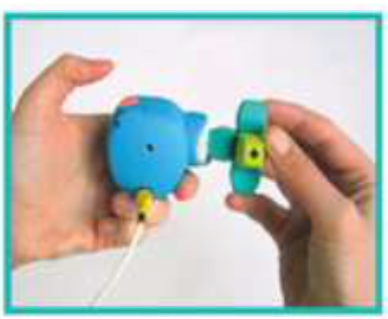

turn the axis with a motion

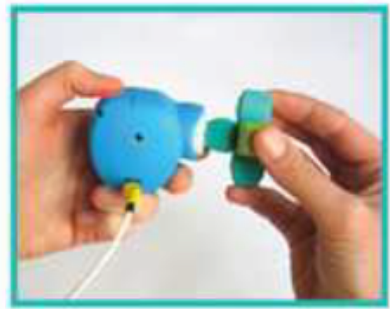

press the button to record

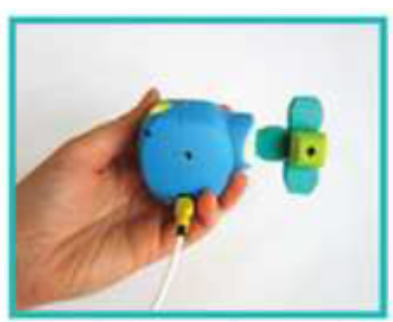

press the button for playback
Figure 2: Programming a Topobo active piece 
$\mathrm{LEGO}^{\mathrm{TM}}$. LEGO ${ }^{\mathrm{TM}}$ is a toy familiar to many, it is a system of interlocking plastic blocks that can be used to build in an open-ended fashion. It is here characterised as 'passive' in contrast to toys that have digital features.

\section{E. Data preparation}

Videos

The videos of the interactions were coded using Observer XT 11.5 software. Every child was coded for each condition of play (LEGO or Topobo) resulting in twenty-two free play observations being coded. Each video has a duration of 20 minutes and was coded into a string of mutually exclusive 'play states' as described in detail in the following section.

\section{Coding scheme development}

Given our objective of describing and analysing interactions during social play, we used a scheme modified from Parten's classic descriptors of social play (Parten, 1932). This scheme was used due to its successful use in previous studies investigating social play (e.g. Farr et al., 2010), however it was modified (described below) to reflect the specific play set-up in our study and to accommodate children with autism (Farr et al., 2010).

We began by watching a subsample of the videos and reflecting on how appropriately these categories meshed with the observed behaviours. As a result of this process it became clear that the distinction between,

"Parallel Play" - Individual chooses to work alongside another participant but does not influence or modify other people's work, and plays beside rather than with.

and

"Solitary Play" - Participant is taking part in the task but is working alone and individually rather than with others.

was impossible to make reliably due to the proximity in which the children were sitting and the observation that even when engaged in individual tasks, children frequently glanced at each other. As a consequence of these observations, the descriptors for the category "Solitary Play" were absorbed into the code for "Parallel Play" and a new code for "Glancing" was introduced (Table I). The new "Glancing" code seemed important because initial observations suggested the behaviour was not associated with long periods of watching others play as described in the traditional code:

"Onlooker Play" - Participant is watching what the other individuals within the group are doing but does not actively take part.

Rather, it seemed that frequent glances of very short duration were quite common, and it did not seem appropriate to code these brief glances as examples of "Onlooker Play". To ensure information about glancing was captured we recorded this behaviour but did not count it as a "Play State", we treated these as "point" behaviours, i.e. duration was treated as zero. Strict parameters distinguished glancing as self-initiated furtive looking, from looking at another child as part of conversation (see supplementary materials).
Further, we wanted to separate peer and object interactions related to the play with the toy from any other social interactions, hence a new code 'Non-play-related conversation' was created to describe verbal exchanges that were centred on topics not directly relevant to the play objects. Note that this code could be used to describe conversation that was playful in itself, e.g. jokes between participants. Finally, we introduced Kirby et al.'s (Kirby, Boyd, Williams, Faldowski, \& Baranek, 2017) criteria for recognising repetitive behaviours considered common of children with autism (Boyd et al., 2010).

The coding scheme used was primarily intended to capture the social quality of observed play. From Table I it can be seen that codes can be roughly divided into more or less socially engaged behaviour.

\section{Reliability}

The coding scheme was used to code the play patterns of both typical and autistic children. Inter-rater reliability on the coding scheme was assessed by two trained coders on eight randomly selected 10-minute sections of video totalling a sample of $36 \%$ of all video. This coding scheme yielded an inter-rater reliability kappa of .72 for the coding of play states. When the "Glances" are coded in the analysis, the inter-rater reliability kappa is .64 .

\section{Data analysis}

Strings of codes for each observation were exported from the Observer software and analysed using Python 3.

The planned analyses for this study are descriptive rather than inferential, given the small sample size and exploratory nature of the study. Our results are based on rich description and observation.

We report durations and frequencies for the Play States, by toy (LEGO or Topobo) and by diagnosis (autistic or typically developing). We planned separate McNemar Chi-square tests for each group, comparing the observed proportions of socially engaged vs non-socially engaged play states (see Table I.), in practice no non-social states were observed for TD children so we only report this for the ASD group. We also report the likelihoods of observed transitions between the different Play States, using the method described by D'Mello (D’Mello, 2012; D’Mello \& Graesser, 2012). These likelihoods are calculated from the probability of moving from one Play State to another based on the current Play State, and account for the baseline frequencies of the Play States in the whole dataset.

\section{Results}

\section{A. Play State Descriptions}

Tables II. and III. give descriptive examples of the behavioural coding. These illustrate some of the behaviours that occurred at the transitions between different play states. The final 4 states coded in Table II give an example of how properties of the TUI toy afforded co-operative play. All the children were motivated to make the toy move and this could only be achieved through collaboration with others to use the 'active' component of the Topobo. 
Table I: Coding categories

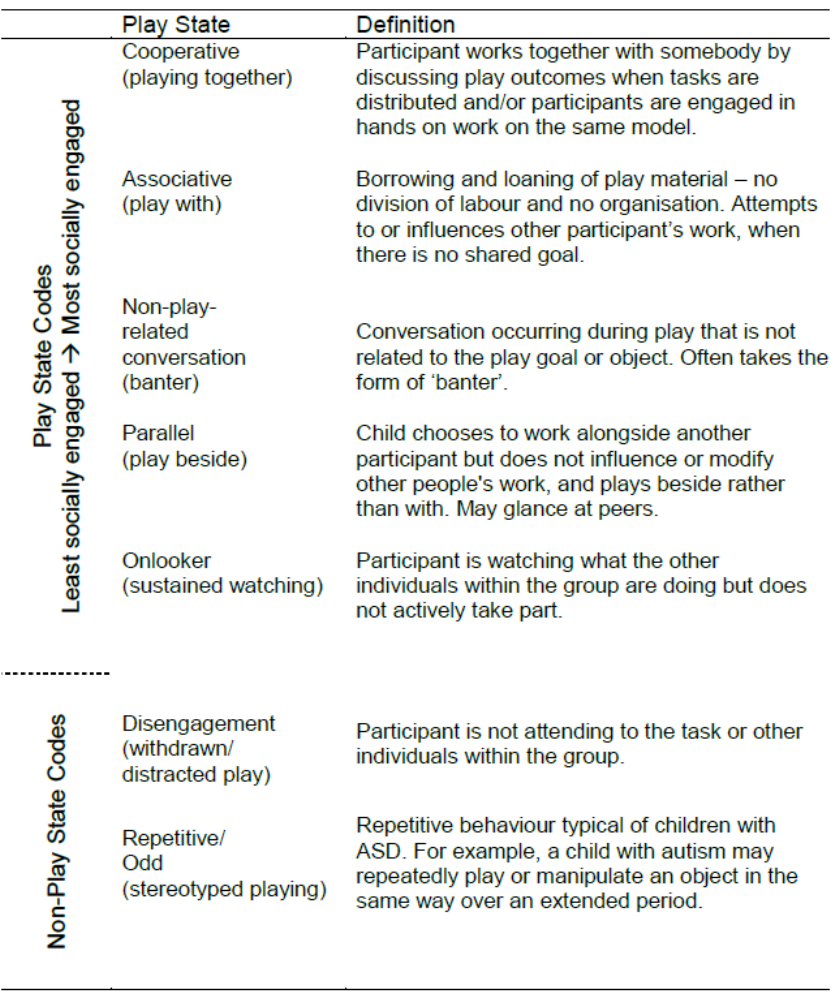

Table II: Sample of Play State transitions: ASD groups A \& B - TUI Toy

\begin{tabular}{|c|c|c|c|}
\hline \multirow{2}{*}{\multicolumn{4}{|c|}{ GROUPA }} \\
\hline & & & Behaviour \\
\hline [00:04:20] & Child 1 & (parallel) & [working on own model] \\
\hline [00:04:27] & Child 1 & (associative) & $\begin{array}{l}\text { [adds a piece to his model] This time mine one has got } \\
\text { horns! }\end{array}$ \\
\hline [00:04:29] & Child 1 & (cooperative) & $\begin{array}{l}\text { Iturns model and points horns towards 2's model, which is } \\
\text { programmed to move side to side] }\end{array}$ \\
\hline [00:04:30] & Child 3 & (associative) & $\begin{array}{l}\text { [stretches arm to stop a collision between } 1 \text { and 2's models] } \\
\text { Oh! No, no! }\end{array}$ \\
\hline [00:04:36] & Child 1 & (cooperative) & $\begin{array}{l}\text { [continues pointing the horns of the model towards 2's model, } \\
\text { roars] He comes to kill you! Don't make it kill you! }\end{array}$ \\
\hline [00:04:50] & Child 2 & (cooperative) & [2's model stops moving, 2 unplugs the cable and hands it to 1] \\
\hline [00:04:55] & Child 1 & (cooperative) & [knocks down B's model] \\
\hline [00:04:56] & Child 3 & (cooperative) & $\begin{array}{l}\text { Joins the knocking down of B's model by using own model to } \\
\text { start hitting B's model, makes battle noises] }\end{array}$ \\
\hline [00:04:56] & $\begin{array}{l}\text { Children } \\
1,2,3\end{array}$ & (cooperative) & [all children laughing] \\
\hline \multicolumn{4}{|l|}{ GROUP B } \\
\hline Time & Child & State & Behaviour \\
\hline [00:04:42] & Child 1 & (parallel) & [trying to plug in power cable in his model] \\
\hline [00:04:48] & Child 2 & (onlooker) & [observes 1's activity] \\
\hline [00:04:54] & Child 2 & (associative) & [looking at 1 , stands up] No, $n o, n o$ ! No, no! No! \\
\hline [00:04:59] & Child 1 & (associative) & [quits activity and looks at 2] \\
\hline [00:05:00] & Child 2 & (cooperative) & Plug it in in mine if you want any power! \\
\hline [00:05:02] & Child 1 & (cooperative) & [plugs in cable in 2's model] \\
\hline [00:05:08] & $\begin{array}{l}\text { Childre } \\
\mathrm{n} 1 \& \text { \& }\end{array}$ & (cooperative) & $\begin{array}{l}\text { [models are interconnected and both children start programming } \\
\text { models] }\end{array}$ \\
\hline [00:05:30] & $\begin{array}{l}\text { Childre } \\
\mathrm{n} 1 \& 2\end{array}$ & (cooperative) & [Knocking and hitting models against each other, making noises] \\
\hline
\end{tabular}

Table III: Sample of Play State transitions: ASD groups A \& B - Passive Toy

\begin{tabular}{|c|c|c|c|}
\hline GROUP A & & & \\
\hline Time & Child & State & $\begin{array}{c}\text { Behaviour } \\
\end{array}$ \\
\hline [00:15:25] & Child 1 & (associative) & [picks up model, litts it and pretends to sail] Speed boat! \\
\hline [00:15:27] & Child 1 & (parallel) & [outs it down and continues building] \\
\hline [00:15:36] & Child 1 & $\begin{array}{l}\text { (non-play } \\
\text { conversation) }\end{array}$ & [giggles] Speedier than 3 crashes in those boxes! \\
\hline [00:15:40] & Child 2 & (associative) & [leans towards 2] What's that craft you've made again? \\
\hline [00:15:42] & Child 1 & (associative) & Harbercraft. \\
\hline [00:15:43] & Child 2 & (associative) & Harbercraft? \\
\hline [00:15:45] & Child 3 & $\begin{array}{l}\text { (non-play } \\
\text { conversation) }\end{array}$ & [laughing] Harbercraft, dummies! \\
\hline [00:15:47] & Child 2 & $\begin{array}{l}\text { (non-play } \\
\text { conversation) }\end{array}$ & [leans and whispers to 1] Why don't you use 3 as the engine? \\
\hline [00:15:48] & $\begin{array}{l}\text { Child } 1 \\
\& 2\end{array}$ & $\begin{array}{l}\text { (non-play } \\
\text { conversation) }\end{array}$ & [both look at child 3 and burst in laughter] \\
\hline [00:15:50] & Child 3 & $\begin{array}{l}\text { (non-play } \\
\text { conversation) }\end{array}$ & What are you looking at? \\
\hline [00:15:53] & Child 2 & $\begin{array}{l}\text { (non-play } \\
\text { conversation) }\end{array}$ & [looking at 2 laughing] Nothing, nothing! \\
\hline [00:15:56] & Child 3 & $\begin{array}{l}\text { (non-play } \\
\text { conversation) }\end{array}$ & I know you are laughing at me! \\
\hline [00:16:00] & Child 2 & $\begin{array}{l}\text { (non-play } \\
\text { conversation) }\end{array}$ & Not at you! With you! \\
\hline \multicolumn{4}{|l|}{ GROUP B } \\
\hline Time & Child & State & Behaviour \\
\hline [00:01:34] & Child 1 & (parallel) & [picks up two towers of blocks] \\
\hline [00:01:38] & Child 1 & (repetitive) & [repetitively knocks the two towers against one another] \\
\hline [00:01:45] & Child 2 & (associative) & [looking at 1] Two hopping legs! \\
\hline [00:01:48] & Child 1 & $\begin{array}{l}\text { (non-play } \\
\text { conversation) }\end{array}$ & [stops knocking the objects] It's not hopping, you're hopping! \\
\hline [00:01:50] & Child 2 & $\begin{array}{l}\text { (non-play } \\
\text { conversation) }\end{array}$ & Well, something is hopping! \\
\hline
\end{tabular}

\section{B. Play State Frequencies and Durations}

Figure 3. shows the observed frequencies of the different Play States (see Table III.) by Diagnostic Group and by Toy Type. Across all groups and Toy Types, Parallel Play was the most frequently observed Play State (frequency $(f q)=467$ ), followed by Associative Play ( $\mathrm{fq}=217)$, Co-operative Play $(\mathrm{fq}=139)$ and Onlooker Play $(\mathrm{fq}=102)$. No 'non-social' states were observed in the TD group. For the ASD group nonsocial states accounted for $12.14 \%$ and socially engaged states for $87.86 \%$ of observed states in the Passive condition, and non-social $=5.03 \%$ socially engaged $=94.97 \%$ of observed states in the TUI condition $($ McNemar $\chi 2(1)=158.35, \mathrm{p}<.001)$.

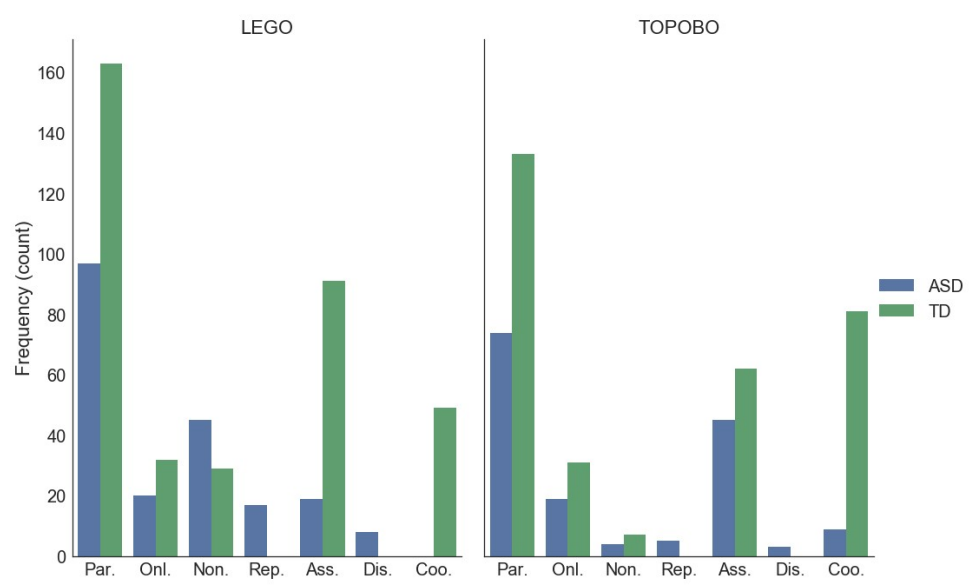

Figure 3: Frequencies of Play States by toy type and diagnosis

Typically developing children have higher frequencies of occurrence for all Play States with the exception of NonPlay related conversation (LEGO condition only), Repetitive Behaviour and Disengagement.

The durations of the Play States, combined across all possible states are shown in Figure 4. Median scores are fairly similar between typically developing and autistic par- 
ticipants; however it is interesting to note that the autistic group have more values in the upper part of the distribution.

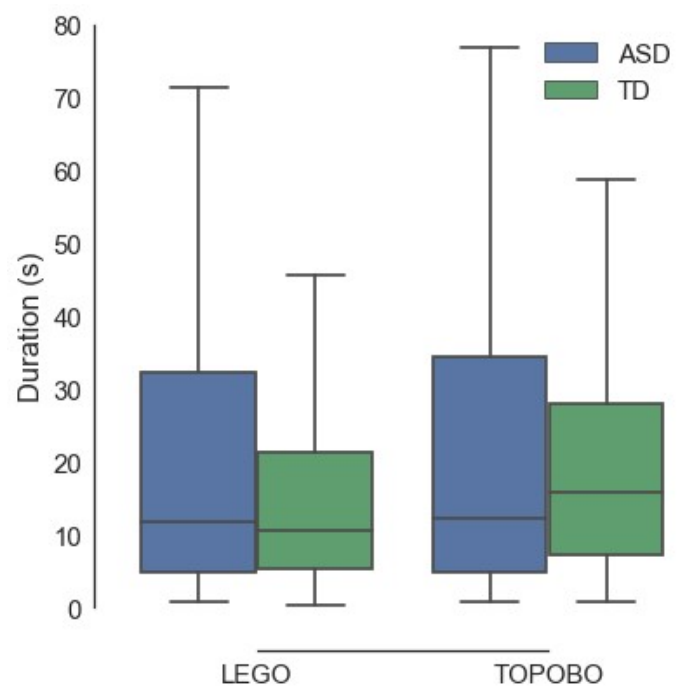

Figure 4: Distribution of combined Play State durations by toy type and diagnosis. NB Outliers have been removed for data visualisation purposes but are included in all analyses.

Breaking this down further, Figure 5., shows the duration (seconds) for each of the Play States codes separately. No occurrences of co-operative play states were observed in the LEGO condition for the children with ASD. It is striking that the participants with ASD engaged in longer episodes of co-operative play with the Topobo, when compared to the typically developing participants. Qualitatively, the difference in duration reflects sustained engagement with the digital interaction component of Topobo among children with ASD. This was particularly pronounced in one of the ASD groups, where children spent the majority of their play time connecting each other's constructions and programming them to move together in an interactive manner.
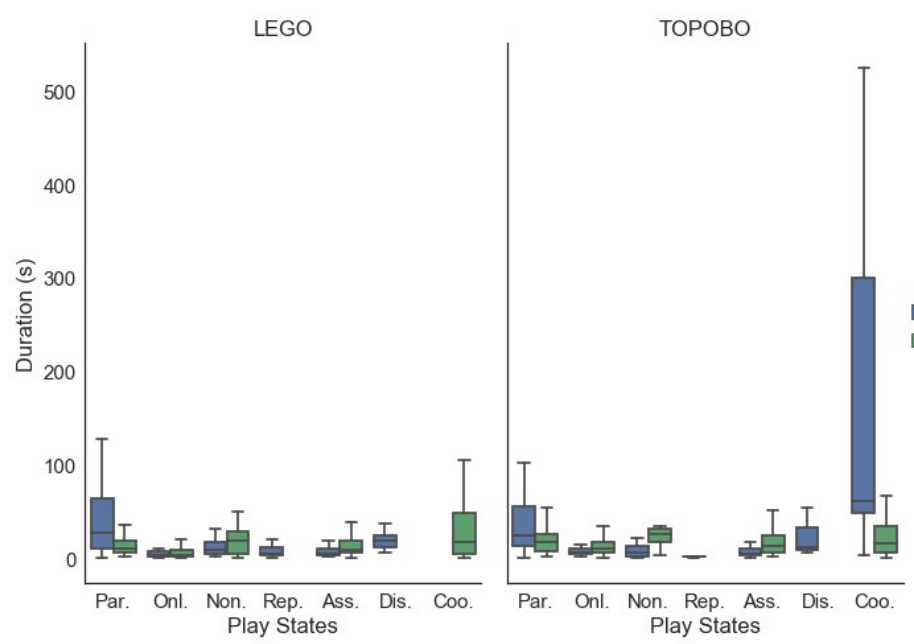

Figure 5: Distribution of separate Play State durations by toy type and diagnosis

\section{Transition likelihoods}

The likelihoods of transitions between the different Play States are illustrated in Figures 6-7. Play States are shown in circles and the arrows connecting the circles represent transitions between them. The direction of the arrow shows the direction of the transition, and the weight (thickness) of the arrow increases with the value of the transitional likelihood. Only those transition likelihoods $>.01$ are shown in these figures. These diagrams can also be usefully interpreted with reference to the frequency information in Fig. 3.

In the following sections we provide some descriptive analysis of key observations from these data, followed by a summary Table (Table IV.)
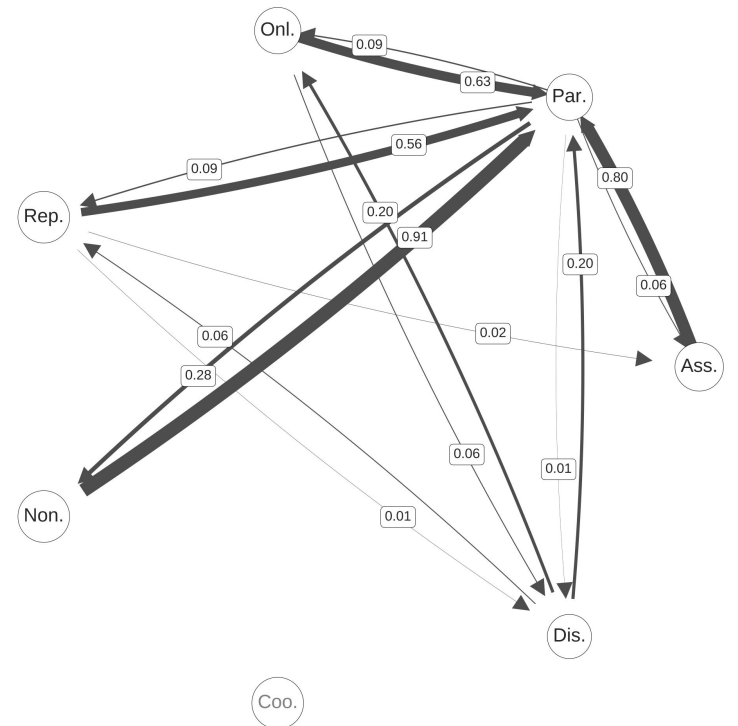

(a) ASD Group

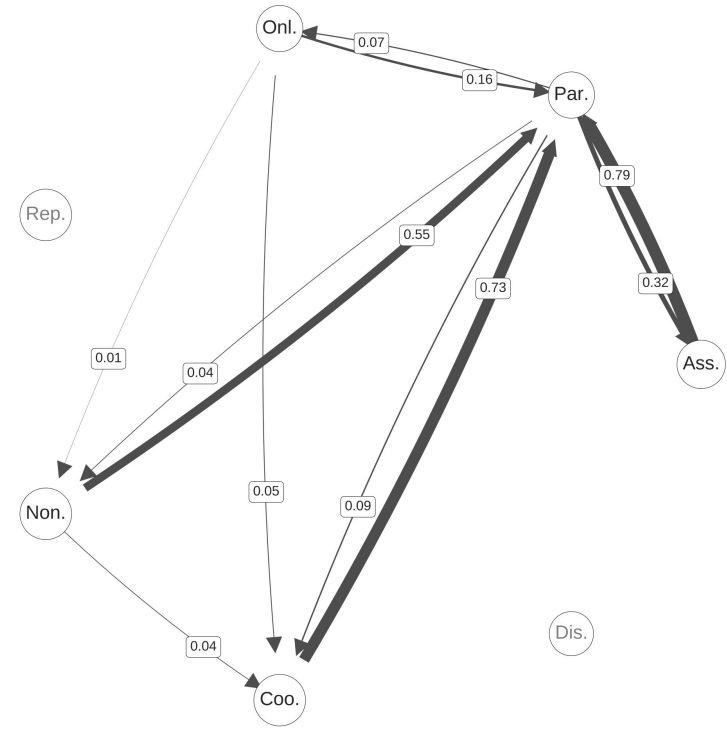

(b) TD group

Figure 6: Transition likelihoods passive toy (LEGO) condition for ASD (6a) and TD groups (6b) 


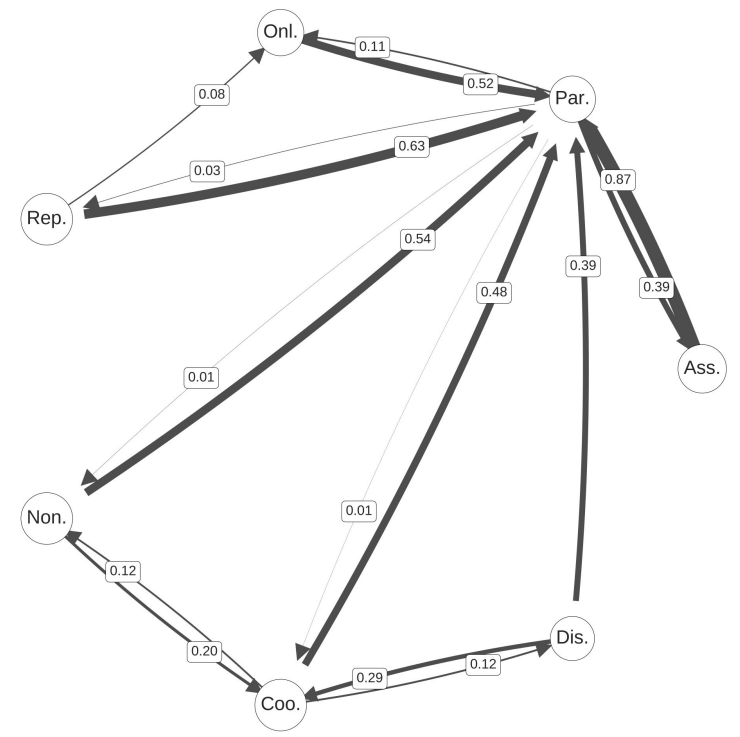

(a) ASD group

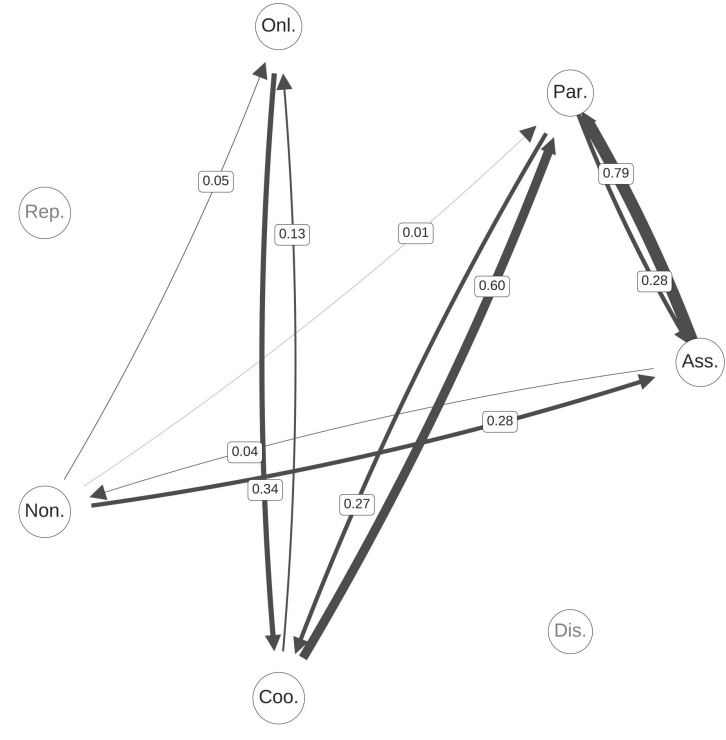

(b) TD group

Figure 7: Transition likelihoods TUI condition (Topobo) for ASD (7a) and TD groups (7b)

\section{Passive Toy}

Figures 6(a) and 6(b) show the transitions between the Play States for the ASD group and TD group respectively in the passive toy condition. Firstly, note that there are some similarities concerning the patterns of transition between Play States for both TD and ASD groups. Being in the Associative Play state was in both cases associated with a relatively strong likelihood of transitioning to Parallel Play, as was being in the "Non-Play-Related Conversation" state.

For the ASD group (6a), starting from all of the observed states, there was at least a $20 \%$ likelihood of transition to the Parallel Play state. Interestingly, the non-Play states of Repetitive Behaviour and Disengagement had likelihoods of transitioning to Parallel Play of $\mathrm{L}=0.56$ and $\mathrm{L}=0.2$ respectively.
In addition, being in the disengaged state was associated with moving to an Onlooker Play state with equal likelihood $(\mathrm{L}=0.2)$ as the Parallel play state. Also note that the likelihood of moving from Disengaged to Repetitive Behaviour is quite low at $\mathrm{L}=0.06$.

For the TD group (6b), being in the Co-operative Play state was associated with a $73 \%$ likelihood of transitioning to the Parallel Play state. In contrast, likelihoods for transitioning into the Co-operative Play state are relatively low, with the highest transition likelihood being from Parallel Play $(\mathrm{L}=0.09)$. Transition likelihoods between Parallel Play and Associative Play (both from and to) are relatively strong for this group. Combined with the frequency information (which is also encoded in the calculation of the likelihoods) it can be seen that most observed states are associated with at least a $16 \%$ likelihood of transition to the Parallel Play state in the passive toy condition.

\section{Tangible User Interface Toy}

Figures 7(a) and 7(b) show the transitions between the Play States for the ASD group and TD group respectively in the TUI toy condition. Again, there are some similarities concerning the patterns of transition between Play States for both TD and ASD groups. Similar to the passive toy condition, being in the Associative Play state was associated with a relatively strong likelihood of transitioning to Parallel Play, $\mathrm{L}=0.87$ for $\mathrm{ASD}$ and $\mathrm{L}=0.79$ for TD. However, an interesting difference here is that while the likelihood of transitioning to Associative Play from Parallel Play for TD children was reasonably similar between Passive $(\mathrm{L}=0.32)$ and TUI $(\mathrm{L}=0.28)$ conditions, for the ASD group this particular transition was much more likely in the TUI condition $(\mathrm{L}=0.39)$ than the passive condition $(\mathrm{L}=0.06)$.

From a comparison of figures $6 \mathrm{a}$ and $7 \mathrm{a}$, it can be seen that all observed states are associated with a relatively high likelihood of transition to Parallel Play (min $\mathrm{L}=0.39$ ). Also note that the ASD group demonstrate co-operative behaviour in the TUI condition only. The transition to Parallel Play $(\mathrm{L}=0.48)$ is the most likely next step from a Co-operative Play state. However, it is very interesting to note that the most likely transitions to the Co-operative Play state are from Non-Play-Related Conversation $(\mathrm{L}=0.20)$ and Disengagement $(\mathrm{L}=0.29)$. Similar to the pattern observed in fig. 6a the Repetitive Behaviour state was associated with transition to Parallel Play, however there was also an $8 \%$ likelihood of a transition to the Onlooker Play state - something not observed in the passive condition.

For the TD group, it is noteworthy that the likelihoods of transition into the Co-operative play state have increased compared to the Passive condition, OnlookerCo-operative $\mathrm{L}=0.36$ and ParallelCo-operative $\mathrm{L}=0.27$.

A comprehensive summary of the transition likelihoods for all conditions can be found in Table IV. 
Table IV: Summary of transition likelihoods $>1 \%$ across all conditions

\begin{tabular}{|c|c|c|c|c|}
\hline & ASD-LEGO & АSD-ТОРОво & TD-LEGO & ТD-тоРово \\
\hline NON. $\rightarrow$ ASS. & - & - & - & \begin{tabular}{|l|}
0.28 \\
\end{tabular} \\
\hline NON. $\rightarrow$ COO. & - & \begin{tabular}{|l|}
0.20 \\
\end{tabular} & 0.04 & - \\
\hline NON. $\rightarrow$ ONL. & - & - & - & 0.05 \\
\hline NON. $\rightarrow$ PAR. & 0.91 & 0.54 & 0.55 & 0.01 \\
\hline ASS. $\rightarrow$ NON. & - & - & - & 0.04 \\
\hline ASS. $\rightarrow$ PAR. & 0.80 & 0.87 & 0.79 & 0.79 \\
\hline COO. $\rightarrow$ NON. & - & 0.12 & - & - \\
\hline coo. $\rightarrow$ Dis. & - & 0.12 & - & - \\
\hline COO. $\rightarrow$ ONL. & - & - & - & 0.13 \\
\hline COO. $\rightarrow$ PAR. & - & 0.48 & 0.73 & 0.60 \\
\hline DIS. $\rightarrow$ coo. & - & \begin{tabular}{|l|l|}
0.29 \\
\end{tabular} & - & - \\
\hline DIS. $\rightarrow$ ONL. & \begin{tabular}{|l|l|}
0.20 \\
\end{tabular} & - & - & - \\
\hline DIS. $\rightarrow$ PAR. & 0.20 & \begin{tabular}{|l|}
0.39 \\
\end{tabular} & - & - \\
\hline DIS. $\rightarrow$ REP. & 0.06 & - & - & - \\
\hline ONL. $\rightarrow$ NON. & - & - & 0.01 & - \\
\hline ONL. $\rightarrow$ COO. & - & - & 0.05 & \begin{tabular}{|l|l|}
0.34 \\
\end{tabular} \\
\hline ONL. $\rightarrow$ DIS. & 0.06 & - & - & - \\
\hline ONL. $\rightarrow$ PAR. & \begin{tabular}{|l|}
0.63 \\
\end{tabular} & \begin{tabular}{|l|}
0.52 \\
\end{tabular} & 0.16 & - \\
\hline PAR. $\rightarrow$ NON. & \begin{tabular}{|l|l|}
0.28 \\
\end{tabular} & 0.01 & 0.04 & - \\
\hline PAR. $\rightarrow$ ASS. & 0.06 & \begin{tabular}{|l|l|}
0.39 \\
\end{tabular} & 0.32 & \begin{tabular}{|l|}
0.28 \\
\end{tabular} \\
\hline PAR. $\rightarrow$ COO. & - & 0.01 & 0.09 & \begin{tabular}{|l|}
0.27 \\
\end{tabular} \\
\hline PAR. $\rightarrow$ DIS. & 0.01 & - & - & - \\
\hline PAR. $\rightarrow$ ONL. & 0.09 & 0.11 & 0.07 & - \\
\hline PAR. $\rightarrow$ REP. & 0.09 & 0.03 & - & - \\
\hline REP. $\rightarrow$ ASS. & 0.02 & - & - & - \\
\hline REP. $\rightarrow$ DIS. & 0.01 & - & - & - \\
\hline REP. $\rightarrow$ ONL. & - & 0.08 & - & - \\
\hline REP. $\rightarrow$ PAR. & 0.56 & \begin{tabular}{|l|}
0.63 \\
\end{tabular} & - & - \\
\hline
\end{tabular}

Child-by-child results

Finally, in figures 8 and 9 we present the coding diagrams that illustrate the second-by-second coding for each child. This demonstrates different patterns of interaction as they unfold in time and illustrates the individual variability (and group variability) in interaction sequences. Figures $8 \mathrm{a} \& 8 \mathrm{~b}$ show the TUI condition.

Figures 9a \& 9b show the passive toy condition.

\section{Discussion}

This study provides further evidence that social isolation is not an inevitable consequence of using digital technology in play. As discussed elsewhere in the literature, well-designed technology can act as a 'bridge' and as a 'buffer' to allow children with and without ASD to mediate playful interactions at their own pace (Parsons, Yuill, Brosnan \& Good, 2015). The current findings provide evidence that a digital construction toy enabled with a Tangible User Interface (TUI) engenders more frequent socially engaged play behaviours during free play, when compared to a passive construction toy. The fine-grained observations conducted in this study therefore demonstrate the potential of tangible interfaces that make effective use of the design principles of embodiment in encouraging children to 'look up' and explore possibilities for social engagement during digital play.
For the case of ASD in particular, this type of interface may be beneficial as it has been designed with sensory aspects of embodiment in mind. Sensory needs occur in $92 \%$ of individuals with autism (Green et al 2016) leaving large variation in strengths and deficits, such as in a person's motor movements and tactile profile. Multi-modal devices leverage hands-on interaction and promote and possibly ameliorate grounded play, thereby using embodiment to assist in the creation of meaningful object interaction. Further, multi-modal objects such as Topobo allow individuals the opportunity to externally model shapes based on the Fibonacci number series (Raffles et al 2004) as well as attend to objects that cross the physical and digital divide. Objects, and digitally enhanced Tangible User Interfaces (TUIs) supersede abstract visual representation as they embody initial motor micromovements found early in life (Torres et al 2013).

We also consider that there are more general reasons why Topobo may have mediating effects on contingent social interaction. Firstly, the rounded, graspable toys were designed to evoke living creatures and all children seemed to enjoy this aspect. The digital interface, moreover, provided a strong motivator that encouraged children to create 'creatures', which could then be programmed to move. The digital embodiment therefore seemed to transfer to a social motivation. There was also an element of 'scarce resource' in that there was only one 'active' component in each playset. Therefore, children had to collaborate in order to programme their toys. However, it is well known that competition for resources can spark conflict as well as co-operation (Asendorpf \& Nunner-Winkler, 1992) and therefore it is interesting to note that this interface promoted the latter rather than the former. In summary, there is evidence that the social play affordances of Tobopo are mediated multifariously; via its physical (shape, physical connectivity), digital (motivation, programmable 'active') and social (scare resource) aspects.

Another important finding from this study is that an externally imposed (i.e. adult directed) play goal is not always necessary to promote socially-oriented play. Digital 'free play' with few boundaries can be mediated through a construction TUI and extends activity even where there is no specific goal (e.g. Farr et al., 2010). With reference to modern conceptualisations of affordance (Pozzi et al., 2016), practitioners may consider the 'pre-conditions' of social engagement during play, not only in terms of preordained activities, but in the thoughtful provision of digital objects that may lend themselves to social play. This may enable children to access the creative benefits of freely determined object manipulation, which has been putatively associated with social and emotional well-being (Gibson, Cornell, \& Gill, 2017). Additionally, our study provides further support that digital technology provided to groups of peers may facilitate important peer relationships between autistic classmates (Holt \& Yuill, 2014). Given the importance of peer relationships for learning in the sociocultural model, this is valuable knowledge for educators.

Related to the idea of child-led play, another finding of interest in this study was that the 'non-social' states of Disengagement and Repetitive Behaviour were more likely 

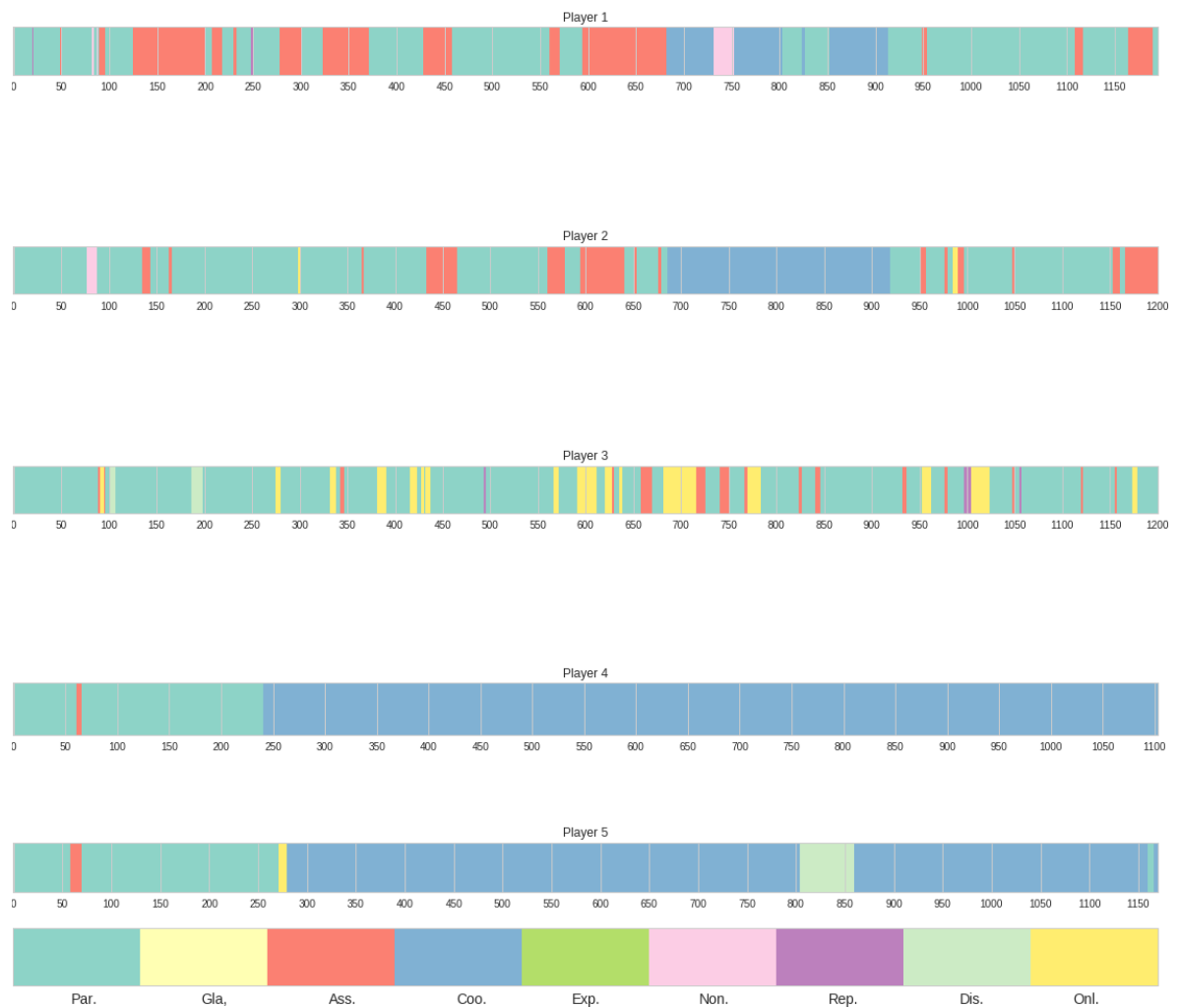

(a) ASD Group
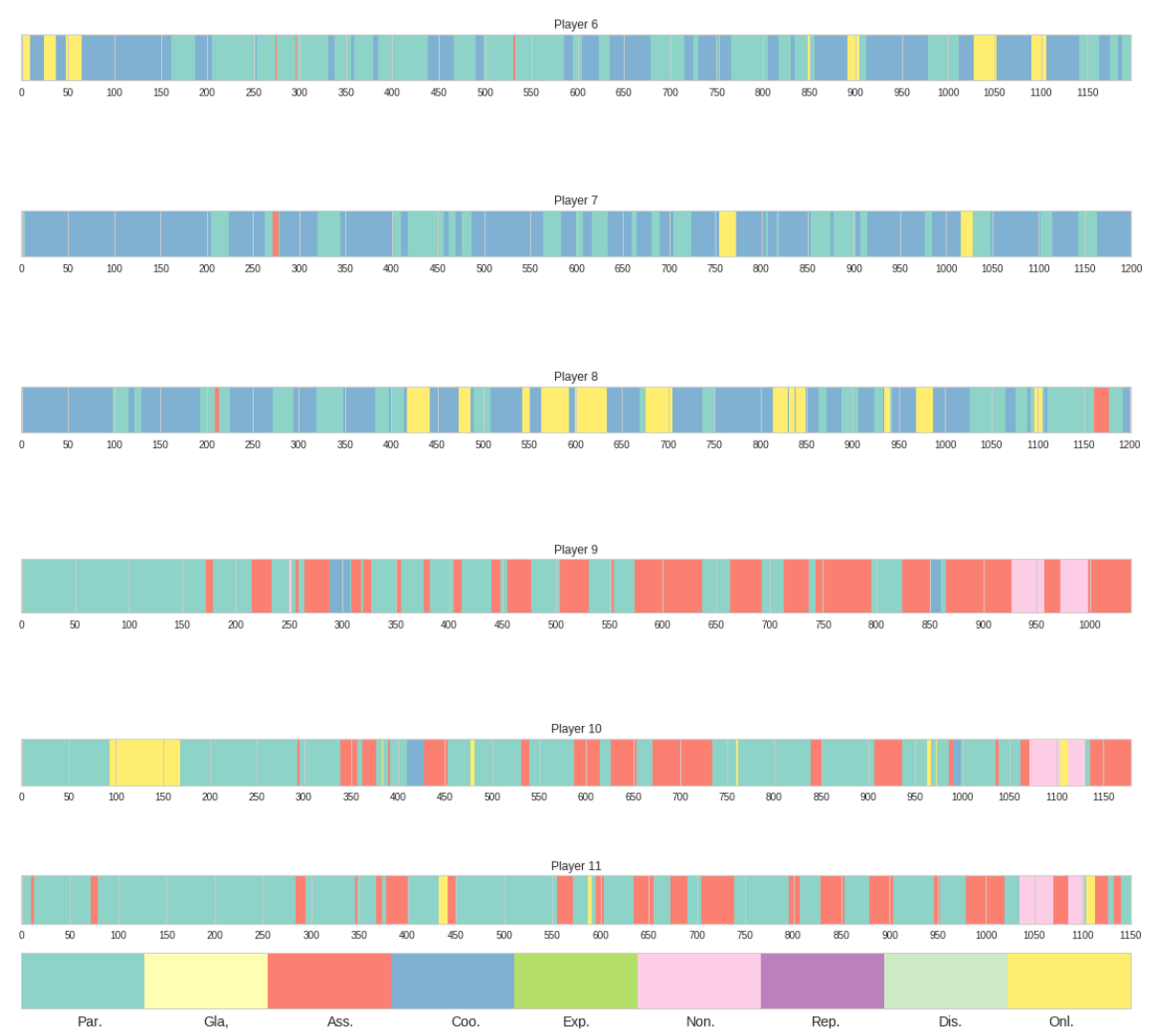

(b) TD Group

Figure 8: Individual transition data (timeseries, time in seconds) for TUI condition (Topobo) for ASD (8a) and TD groups $(8 \mathrm{~b})$ 

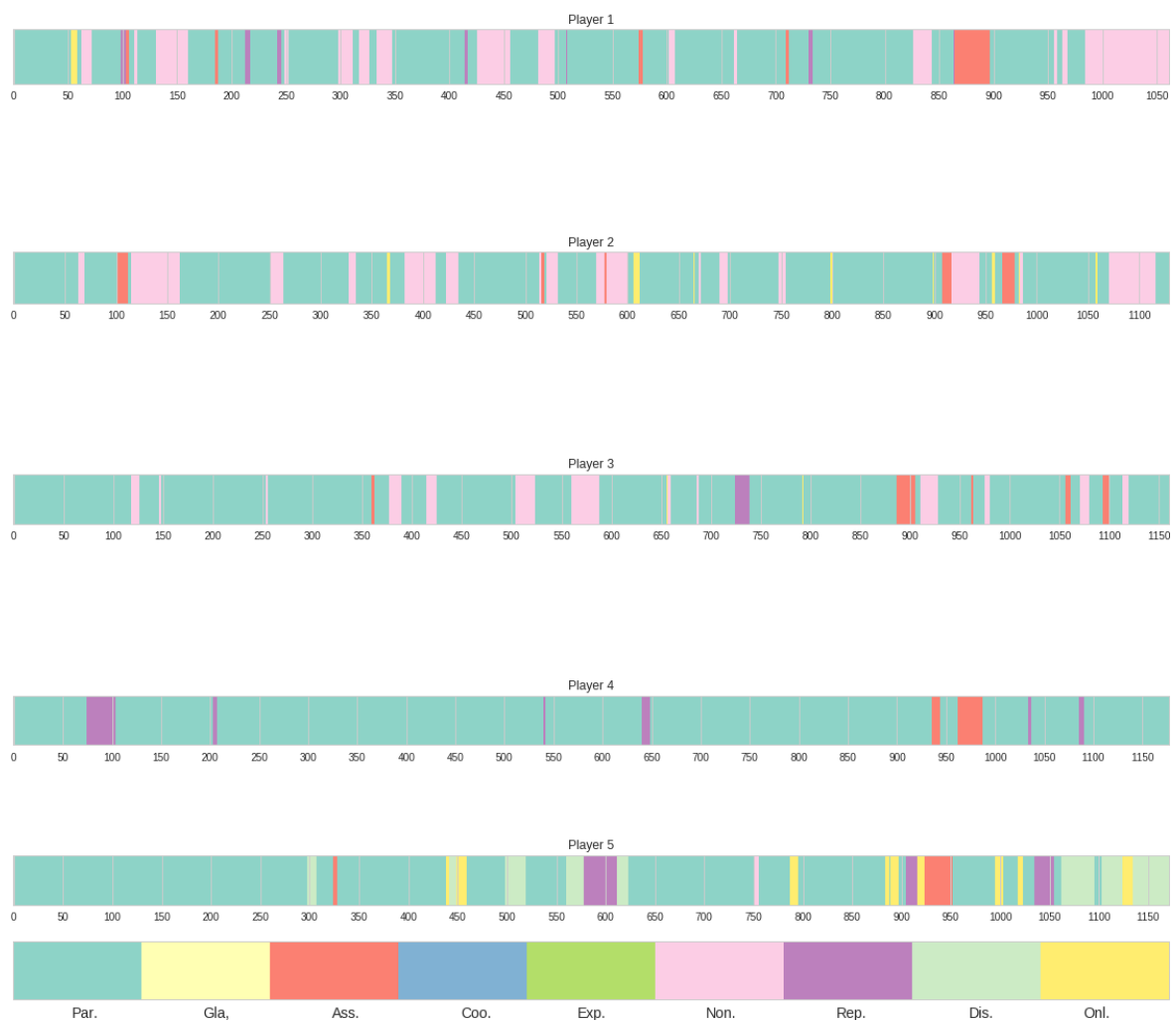

(a) ASD Group
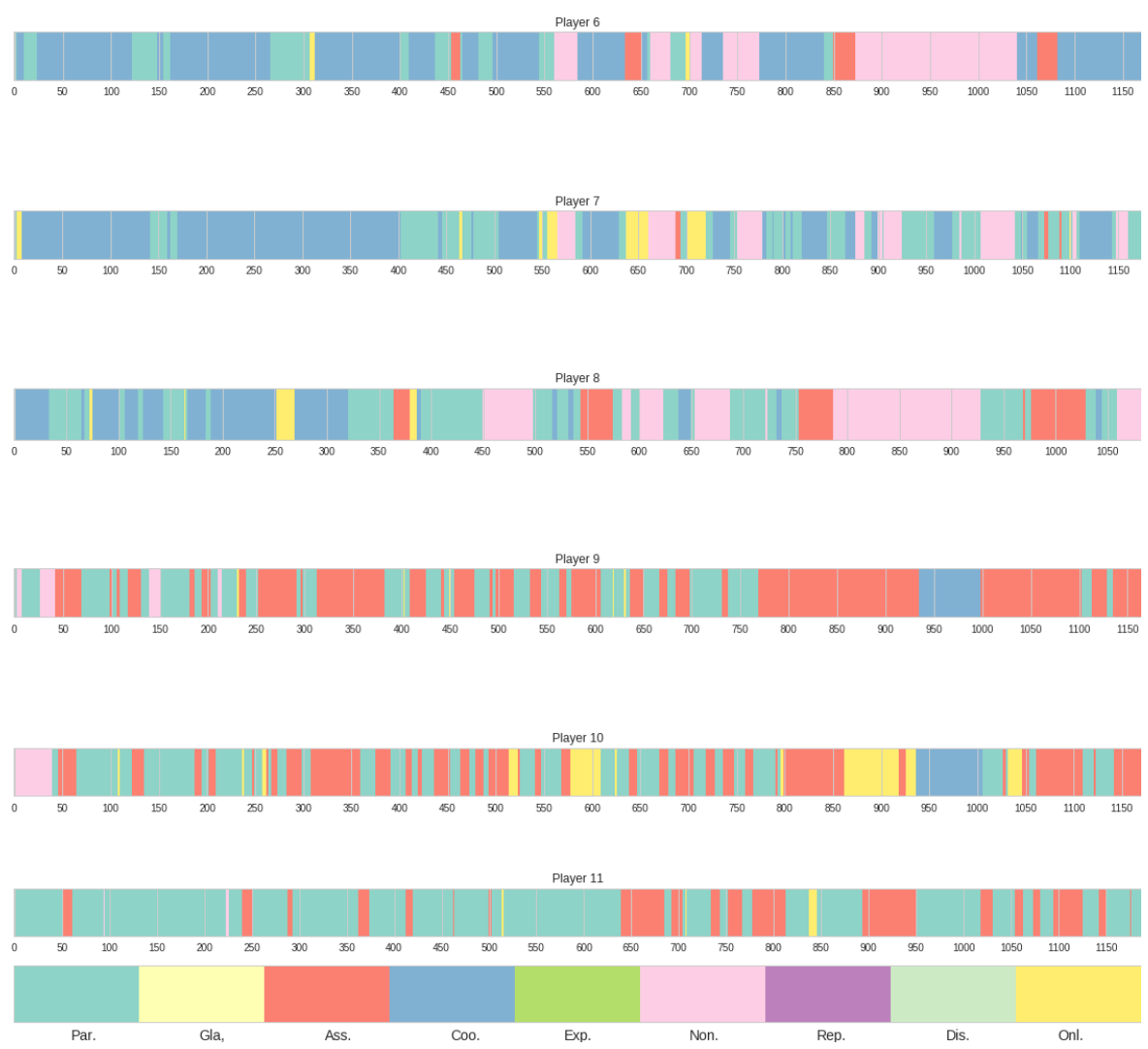

(b) TD Group

Figure 9: Individual transition data (timeseries, time in seconds) for passive toy condition (LEGO) for ASD (9a) and TD groups (9b) 
to be followed by a transition into a socially engaged Play State than by another non-social state. A transition likelihood between non-social states meeting our $1 \%$ threshold was observed only in the ASD Passive Condition between Disengagement and Repetitive behaviour $(\mathrm{L}=0.06)$ and viceversa $(\mathrm{L}=0.01)$. In the TUI condition, the non-social state of Disengagement was actually associated with a $20 \%$ likelihood of transitioning to Co-operative Play, a state not observed in the passive condition for this group. We suggest that this means that seemingly disengaged or repetitive behaviour should not be automatically dismissed as non-functional, or obstructive of social development. This links with observations from researchers (Dawson et al., 2017; Mottron, 2017) who stress the importance of neurotypical researchers or practitioners engaging with the autistic experience. It is also consistent with the constructionist perspective discussed in the introduction (Ackerman, 1996; Papert, 1994), repetitive behaviours could be viewed here as a different way of engaging in the 'stepping back' aspects of learning.

The longer duration of co-operative behaviour in autistic compared to typically developing children is interesting with respect to manifestations of social play behaviour. It could be that the affordance of the TUI for those with ASD means social states become more attractive for longer periods. Children are motivated and engaged, and following from that experience, play becomes a valuable social tool. In contrast, TD children had a greater frequency of co-operative behaviour, perhaps aligned with smoother transitions using the 'diving in and stepping out model' of play engagement (Ackermann, 1996). A wider and freer view on interaction enables what Ackermann (1996) calls 'perspective-taking' where the presentation of an object or display promotes engagement from varying vantage points, this approach could be invaluable for neurodiverse children (Dalton, 2013).

This observed difference in frequency vs duration, raises thought-provoking methodological point. On the one hand the Play States coding scheme could be considered to impose a normative perspective, given its implicit hierarchy of socially engaged and non-social play behaviours. This is potentially controversial in the children's rights literature generally (International Play Association, 2017), and also in the autistic rights literature specifically (McGuire, 2016). On the other hand, it does facilitate a flexible analysis of playful interactions as they unfold over time. There is no clear resolution to this tension, however with careful framing we hope that it is clear that there is intrinsic value in play for its own sake, regardless of how it is expressed, and also that using tools such as this can provide information to help the development of informed perspectives on digital and nondigital toys for different populations.

It is also important to consider the present findings within the limitations of the research design. The study is smallscale and the results are not intended to be representative and used to make statistical inferences about wider populations. For example, we observed that one of the ASD groups was extremely engaged in co-operative play with the digital component of Topobo, whilst in another ASD group the co-operative engagement with Topobo was moderate.
However, as the study was not designed to make inferences at a population level the sample-size means that we cannot control for 'group effects' in the results. Nonetheless, we propose the data reported make an important contribution through providing the rich observational detail that feeds in to theory development and hypothesis testing in future studies. To the best of our knowledge, this is the first study that reports on peer social play behaviour with construction based TUIs in a free-play paradigm and we hope that it will provide a useful benchmark for future research.

As for the direction that future research should take, we suggest that further observational work comparing engagement with different types of TUI, in different contexts and with different play partners could be illuminating. Such research could identify the ways in which TUIs can promote social engagement in a meaningful way for those with autism. The individual time-series results (Figs. 8 \& 9) demonstrate heterogeneity between individuals and groups. Future studies could usefully explore how such diversity arises, considering factors such as the play scenario, individual differences and group dynamics.

Finally, the message for those supporting autistic children, is that digital technologies should not be dismissed as likely to promote solitary behaviour. As others have suggested, a more nuanced perspective considering the affordances of the digital object, and the environment in which it is provided, is required. Based on the present evidence, educators may wish to consider making TUI enabled objects available for play. Moreover, the present study shows that socially collaborative play can be afforded by digital construction toys, which may be more appealing to some children with autism than figurine-based playsets. The embodied engagement afforded by TUIs such as Topobo seems likely to be both appealing for the individual and facilitative of social play, which in turn may support social development.

Acknowledgements: Thanks go to Nicola Yuill and Pablo Romero who were the original $\mathrm{PhD}$ supervisors where this data was initially gathered, St Anthony's Special Needs School, Chichester, Woodingdean Primary School, Brighton and all the children who took part. Thanks to Dr Carlos Lugo for help making the figures. Thanks to LEGO Foundation for funding research assistance.

Funding: Thanks to LEGO Foundation and Economic and Social Research Council grant ES/N006577/1 for funding that contributed to this research.

Conflict of interest declarations: Jenny Louise Gibson, Gill Althia Francis and Silvana Mareva have all received funding from LEGO Foundation. William Farr has no conflicts of interest to declare.

\section{ReFERENCES}

Ackermann, E. K. (1996). Perspective-Taking and Object Construction: Two Keys to Learning. Constuctionism in Practice: Designing, Thinking, and Learning in a Digital World.

Asendorpf, J. B., \& Nunner-Winkler, G. (1992). Children's moral motive strength and temperamental inhibition reduce 
their immoral behavior in real moral conflicts. Child Development, 63(5), 1223-1235.

Boyd, B. A., Baranek, G. T., Sideris, J., Poe, M. D., Watson, L. R., Patten, E., \& Miller, H. (2010). Sensory features and repetitive behaviors in children with autism and developmental delays. Autism Research, 3(2), 78-87.

D’Mello, S., \& Graesser, A. (2012). Dynamics of affective states during complex learning. Learning and Instruction, 22(2), 145-157. http://doi.org/10.1016/j.learninstruc.2011.10.001

D’Mello, S. (2012). Monitoring Affective Trajectories during Complex Learning. In Encyclopedia of the Sciences of Learning (pp. 2325-2328). Springer, Boston, MA. http://doi.org/10.1007/978-1-4419-1428-6

Dalton, N. S. (2013). Neurodiversity HCI. ACM Interactions, 20(2),72-75. http://doi.org/10.1145/2427076.2427091

Dawson, M., Courchesne, V., Mineau, S., Mottron, L., \& Jacques, C. (2017). Repetitive Behavior and Object Exploration in Young Autistic Children: How Are They Associated? Paper presented at International Meeting for Autism Research 2017. San Francisco, CA.

Dourish, P. (2001). Where the Action Is: The Foundations of Embodied Interaction. Cambridge, MA: The MIT Press.

Durkin, K., \& Blades, M. (2009). Young people and the media: Special Issue. British fournal of Developmental Psychology, 27(1), 1-12. http://doi.org/10.1348/026151008X400472

Farr, W., Yuill, N., \& Raffle, H. (2010). Social Benefits of a Tangible User Interface for Children with Autistic Spectrum Conditions. Autism The International Journal of Research and Practice, 14(3), 237-252.

Fernaeus, Y., Tholander, J., \& Jonsson, M. (2008). Beyond representations: towards an action-centric perspective on tangible interaction. International fournal of Arts and Technology, 1(3/4), 249-267.

Fletcher-Watson, S., \& Durkin, K. (2015). Uses of new technologies by young people with developmental disorders. Neurodevelopmental Disorders: Research Challenges and Solutions, 243-267.

Green D, Chandler S, Charman T, Simonoff E, Baird G (2016) Brief Report: DSM-5 Sensory Behaviours in Children With and Without an Autism Spectrum Disorder. Fournal of Autism and Developmental Disorders 46:3597-3606 DOI 10.1007/s10803-016-2881-7

Gibson, J. (1979). The Ecological Approach to Visual Perception. Boston: Houghton-Mifflin Co.
Gibson, J. L., Adams, C., Lockton, E., \& Green, J. (2013). Social communication disorder outside autism? A diagnostic classification approach to delineating pragmatic language impairment, high functioning autism and specific language impairment. Journal of Child Psychology and Psychiatry, 54, 1186-1197. http://doi.org/10.1111/jcpp.12079

Gibson, J. L., Cornell, M. M., \& Gill, T. (2017). A Systematic Review of Research into the Impact of Loose Parts Play on Children's Cognitive, Social and Emotional Development. School Mental Health. 9(4), 295-309 http://doi.org/10.1007/s12310-017-9220-9

Gibson, J. L., Hussain, J., Holsgrove, S., Adams, C., \& Green, J. (2011). Quantifying peer interactions for research and clinical use: The Manchester Inventory for Playground Observation. Research in Developmental Disabilities, 32(6), 2458-2466.

Goodwin, M. S. (2008). Enhancing and Accelerating the Pace of Autism Research and Treatment: The Promise of Developing Innovative Technology. Focus on Autism and Other Developmental Disabilities. http://doi.org/10.1177/1088357608316678

Gray, P. (2013). Play as Preparation for Learning and Life. American Journal of Play, 5(3), 271-292.

Guralnick, M. J., \& Hammond, M. A. (1999). Sequential Analysis of the Social Play of Young Children with Mild Developmental Delays. Journal of Early Intervention, 22(3), 243-256.

Hinske, S., Langheinrich, M., \& Lampe, M. (2008). Towards guidelines for designing augmented toy environments. In Proceedings of the 7 th ACM conference on Designing interactive systems (pp. 78-87). ACM.

Holmes, E. \& Willoughby, T. (2009). Play behaviour of children with autism spectrum disorders. Fournal of Intellectual \& Developmental Disability, 30(3),156-164

Holt, S., \& Yuill, N. (2014). Facilitating other-awareness in low-functioning children with autism and typicallydeveloping preschoolers using dual-control technology. Journal of Autism and Developmental Disorders, 44(1), 236-248. http://doi.org/101007s10803013x

International Play Association (2018) website: http://ipaworld.org/childs-right-to-play/the-childs-rightto-play/ Accessed 02/08/2018

Ishii, H., \& Ullmer, B. (1997). Tangible Bits: towards Seamless interfaces between People, Bits and Atoms. Paper Presented at the CHI Proceedings of the 16th International Conference on Human Factors in Computing Systems Atlanta Georgia, 97 SRC-. 
Jacklin, A., \& Farr, W. (2005). The computer in the classroom: A medium for enhancing social interaction with young people with autistic spectrum disorders? British fournal of Special Education, 32(4), 202-210. http://doi.org/10.1111/j.1467-8578.2005.00398.x

Kirby, A. V, Boyd, B. A., Williams, K. L., Faldowski, R. A., \& Baranek, G. T. (2017). Sensory and repetitive behaviors among children with autism spectrum disorder at home. Autism, 21(2), 142-154. http://doi.org/http://dx.doi.org/10.1177/1362361316632710

Leontyev, A. N. (1959). Problems of the Development of the Mind. (Vol. 1981). Moscow: Progress Publishers.

Levac, D., Rivard, L., \& Missiuna, C. (2012). Defining the active ingredients of interactive computer play interventions for children with neuromotor impairments: A scoping review. Research in Developmental Disabilities, 33(2012), 214-223.

Manning, M. M., \& Wainwright, L. D. (2010). The Role of High Level Play as a Predictor Social Functioning in Autism. Fournal of Autism and Developmental Disorders, 40(5), 523-533.

Maskey, M., Lowry, J., Rodgers, J., McConachie, H., \& Parr, J. R. (2014). Reducing Specific Phobia/Fear in Young People with Autism Spectrum Disorders (ASDs) through a Virtual Reality Environment Intervention. PLoS ONE, 9(7).

McGuire, A. (2016). War on Autism: On the Cultural Logic of Normative Violence. University of Michigan Press.

Mottron, L. (2017). Should we change targets and methods of early intervention in autism, in favor of a strengths-based education? European Child \& Adolescent Psychiatry, 26(7), 815-825. http://doi.org/10.1007/s00787-017-0955-5

Norman, D. A. (1988). The Design of Everyday Things. New York Basic Books.

Norman, D. A. (2007). The next UI breakthrough, part 2. Interactions, 14(4), 46. http://doi.org/10.1145/1273961.1273986

Orsmond, G. I., \& Kuo, H.-Y. (2011). The daily lives of adolescents with an autism spectrum disorder: Discretionary time use and activity partners. Autism, 15(5), 579-599. http://doi.org/10.1177/1362361310386503

Papert, S. (1993). Mindstorms. Children, Computers and Powerful Ideas. Cambridge MA: Perseus

Pares, N., Carreras, A., Durany, J., Ferrer, J., Freixa, P., \& Gomez, D. (2004). MEDIATE: An interactive multisensory environment for children with severe autism and no verbal communication. Paper Presented at the Proceedings of the Third International Workshop on Virtual Rehabilitation
Lausanne Switzerland, 2004 SRC.

Parsons, S., Yuill, N., Brosnan, M. \& Good, J. (2015) Innovative technologies for autism: critical reflections on digital bubbles. Journal of Assistive Technologies, 9(2), 116-121

Parten, M. B. (1932). Social Participation among Pre-School Children. Journal of Abnormal Psychology, 27, 243-269.

Pellis, S. M., \& Pellis, V. C. (2007). Rough-and-tumble play and the development of the social brain. Current Directions in Psychological in Psychological Science, 16(2), 95-98.

Piper, A. M., O’Brien, E., Morris, M. R., \& Winograd, T. (2006). SIDES: Tabletop Computer Game for Social Skills Development. Paper Presented at the CSCW Proceedings of the on Computer Supported Cooperative Work, 6.

Pozzi, G., Pigni, F., Vitari, C., Buonanno, G., \& Raguseo, E. (2016). Business model in the IS discipline: A review and synthesis of the literature. In Lecture Notes in Information Systems and Organisation (Vol. 13, pp. 115-129). http://doi.org/10.1007/978-3-319-22921-8_10

Raffle, H., Parkes, A., \& Ishii, H. (2004). Topobo: Assembly System with Kinetic Memory. Paper Presented at the CHI â€TM Proceedings of the 22nd International Conference on Human Factors in Computing Systems, Austria, Vienna., 4.

Robins, B., \& Dautenhahn, K. (2007). Encouraging social interaction skills in children with autism playing with robots: A case study evaluation of triadic interactions involving children with autism, other people (peers and adults) and a robotic toy. ENFANCE, 59(1), 72-81.

Robinson, C. C., Anderson, G. T., Porter, C. L., Hart, C. H., \& Wouden-Miller, M. (2003). Sequential transition of patterns of preschoolers' social interaction during child-initiated play: Is parallel-aware play a bidirectional bridge to other play states? Early Childhood Research Quarterly, 18(1), 3-21. http://doi.org/10.1016/S0885-2006(03)00003-6

Rogers, Y. (2006). Moving on from Weiser's Vision of Calm Computing: engaging UbiComp experiences. Ubicomp '06. http://doi.org/10.1007/11853565_24

Rogers, Y., Scaife, M., Gabrielli, S., Smith, H., \& Harris, E. (2002). A Conceptual Framework for Mixed Reality Environments: Designing Novel Learning Activities for Young Children. Presence: Teleoperators and Virtual Environments. http://doi.org/10.1162/105474602321050776

Tager-Flusberg, H., \& Anderson, M. (1991). The Development of Contingent Discourse Ability in Autistic Children. Journal of Child Psychology and Psychiatry, 32(7), 1123-1134. http://doi.org/10.1111/j.1469-7610.1991.tb00353.x 
Tartaro, A., \& Cassell, J. (2008). Playing with Virtual Peers: Bootstrapping Contingent Discourse in Children with Autism. Paper Presented at the International Conference of the Learning Sciences Utrecht Netherlands.

Torres, E. B., Brincker, M., Isenhower, R., Stigler, K., Nurnberger, J., \& Metaxas, D. (2013). Autism: the micromovement perspective. Frontiers of Integrative Neuroscience, 7(32). http://doi.org/103389fnint00032

von Hofsten, C. (2007). Action in Development. Developmental Science, 10, 1467-7687. http://doi.org/doi 101111j00564x

Vygotsky, L. (1978). Mind in Society. Cambridge, MA: Harvard University Press.

Weiser, M. (1991). The Computer for the 21st Century. Scientific American, 265(3), 94-104.

Williams, E., Costall, A., \& Reddy, V. (1999). Children with Autism experience Problems with Both Objects and People. fournal of Autism and Developmental Disorders, 29, 367-378.

Wolfberg, P., Bottema-Beutel, K., \& DeWitt, M. (2012). Including children with autism in social and imaginary play with typical peers: Integrated Play Groups model. American fournal of Play., 5(1), 55-80.

Wolfberg, P. J. (2009). Play \& Imagination in children with autism, 2nd ed.

Yuill, N., Strieth, S., Roake, C., Aspden, R., \& Todd, B. (2007). Brief report: Designing a playground for children with autistic spectrum disorders - Effects on playful peer interactions. Fournal of Autism and Developmental Disorders, 37(6), 1192-1196. http://doi.org/10.1007/s10803-006-0241-8 